\title{
Eine neue (zweite) Art von Sabacon aus Nippon
}

\author{
Yasunori Miyosi \\ Matuyana Kütō-Jogakkō, Matuyama
}

Sabacon sato-ikioi nov. spec.

Körper: Die Gestalt des Müunchens ist oval, die des Weibehens ist elliptisch. Die Fläche des Carapax mit vielen, winzigen Stacheln bewehrt. Das erste Thorakalsegment (mit 9-10 winzigen liegenden Stacheln) ist mìt dem Carapax-Hinterraud verwachsen. Das zweite Thorakalsegment ist frei und mit eiver Querreihe borstentragender Höckerchen besetzt (mitten ein schwarzes Dörnchenpaar), und trägt beim Männchen zwei Chitinplättchen. Die 1-5. Abdominaltergite des Mäunchens sind zu einem Scutum verwachsen, 6. und 7. Tergit ist frei und mit je 1 mittleren Chitinplättchej versehen, 8. Tergit frei und mit 2 Chitinplättchen. Beim Wëibchen sind die 1.-8. Tergite frei ; 1. 2. und 7. Tergit mit je 1 mittleren Chitinplättchen, 3. -6. und 8. Tergit mit je 2 Chitinplättchen. Die Abdominaltergite (Chitinplättchen und weichbäutigen Teile) des Männchens und Weibchens sind mit Querreiheu vieler unregelmässig stehender, borstentragender Höckerchen bewehrt. Die Öffnungen der Stinkdrüsen sind auf der Dorsalfäche der 1. Coxen sichtbar. Die Stigmen siud auf dem Stigmenstcrnit sichtbar (Abb. 2, C); jedes hintere Sternit mit einer Querreihe winziger, borstentragender Höckerchen. 
$(50)$

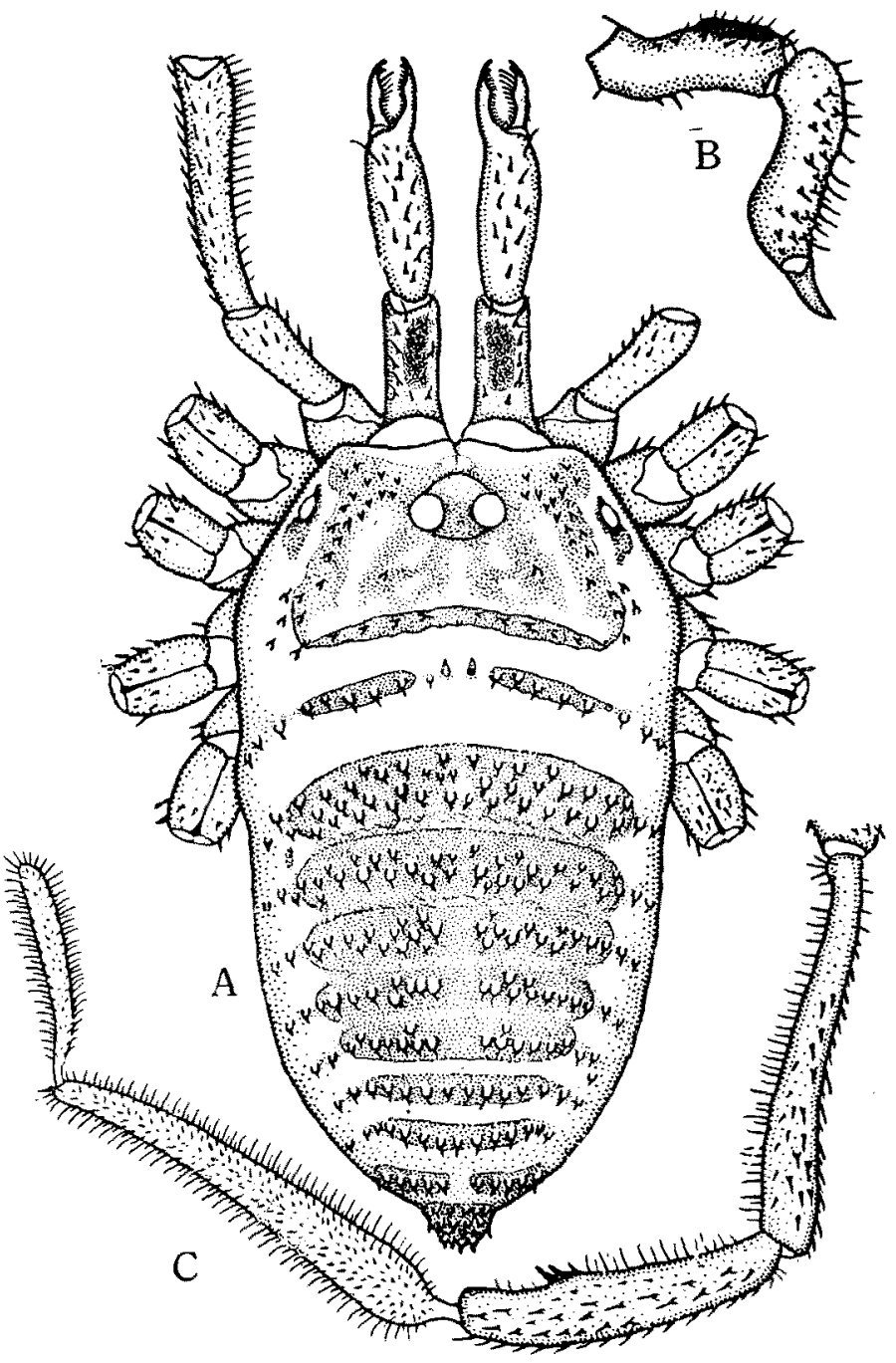

Abb. 1. Sabaron sato-ikioi nov. spec. ô
A, Körper donal B, Chelicere des ô lateral
C, Palpus des of lateral 
Augenhügel: Der Augenhügel ist queroval, relativ niedrig, unbewehrt.

Cheliceren: Die Cheliceren sind kurz und schmal. Die Dorsalseite des 1. Gliedes beim Mäunchen ist etwas geschwollen (Abb. 1, B). Das 2. Glied ist normal. Die beiden Chelicerenglieder sind dorsal mit Börstchen verschen. Die Schueiden der Zauge sind grösstenteils gezähuelt (Abb. 2, D).

Palpen: Die Palpen sind länger a!s der Körper, die des Weibchens sind dicker als die des Münnchens (Abb. 1, C, Abb. 2, A). Patella ist dicker und kürzer als Femur und beim Mäuuchen ventral mit 3 Häkchen versehen, die dem Weibchen fehlen (Abb. 1, C, $\Lambda$ bb. 2, F). Tibia ist länger als Patella und apikal verjüngt. Tarsus kurz und regelmässig dicht bohaart wie Tibia, ohne Endklaue ( $\Lambda$ bb. 1, C, Abb. 2, A).

Beine: Die Beine sind relativ kurz und düun, ohne Bewehrung, nur mit Börstchen und Haaren versehen. Die Metatarsen und Tarsen sind fein, und enden apikal mit je 1 einfacher Klaue (Abb. 2, H).

Masse: Beim Mäunchen; Körper $3.5 \mathrm{~mm}$. Beim Weibchen; Körper $4.5 \mathrm{~mm}$. Die Beinglie lermasse sind wie fulgt (in $\mathrm{mm}$ ).

Beim Männchen :

\begin{tabular}{c|c|c|c|c}
\hline & Fenur & Patella & Tibia & Metatarsus u. Tarsus \\
\hline Be. I & 2.9 & 0.9 & 2.5 & 6.8 \\
\hline Be. II & 3.8 & 1.1 & 3.4 & 10.4 \\
\hline Be. III & 3.0 & 0.9 & 2.6 & 7.6 \\
\hline Be. IV & 4.2 & 1.2 & 3.2 & 10.7
\end{tabular}




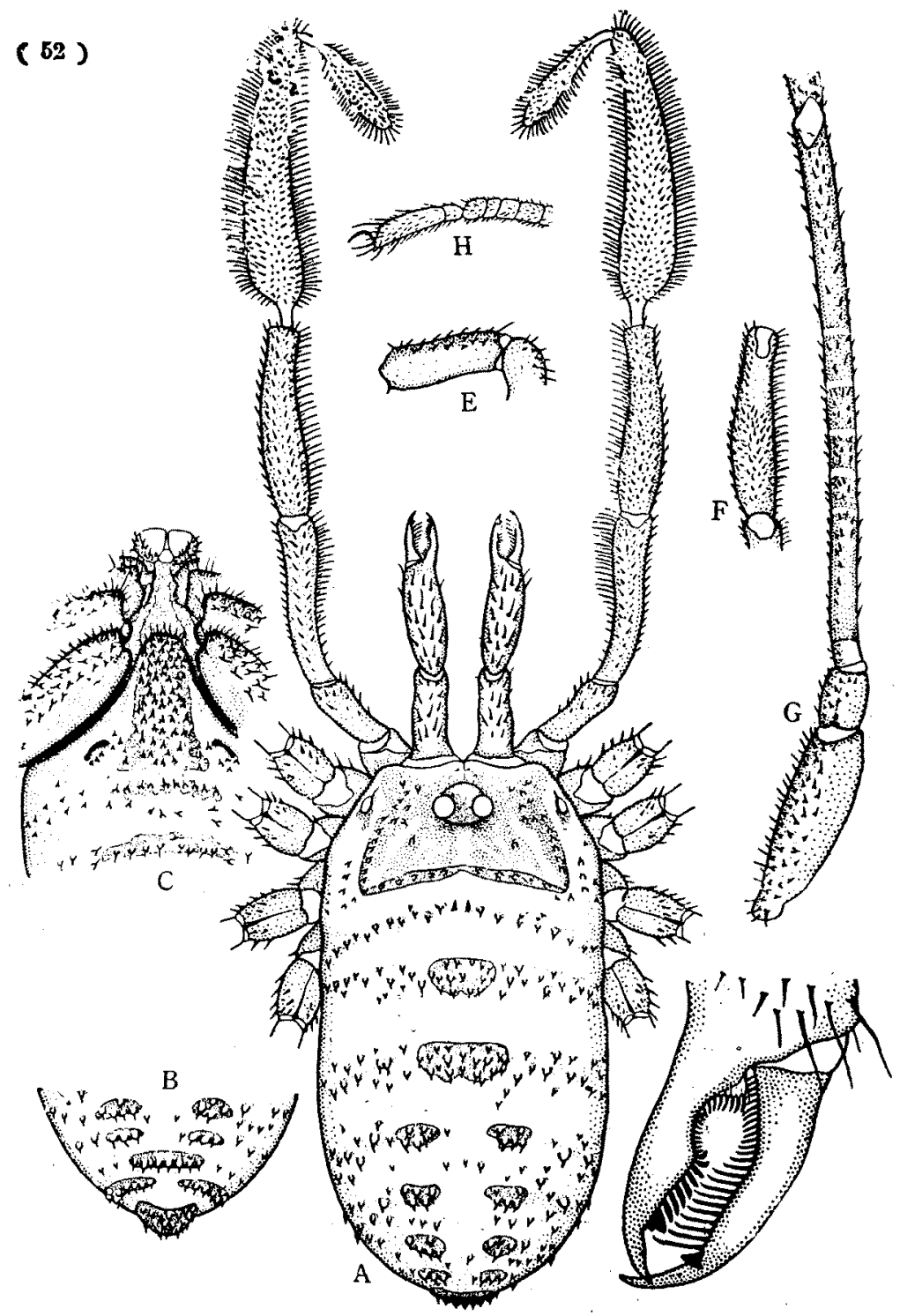

Abb. 2. Sabacon sato-ikioi nov. sp?c. 9

A, Körpar dorsal mit Cheliceren und Palpen B,-5, - 8. Tergite ron dorsıl hinten gesehen C, Ventralansicht des Mittelkörpers D, Endglied der Chelicere ron rorn E, 1. Glied der Chelicere von lateral F, Patella ventral des Weibchens G, IV. Bein von rentral (Coxa, Trochanter und Fenur) H, apikal Tarsus des 1. Beins. 
Beim Weibchen :

\begin{tabular}{c|c|c|c|c}
\hline & Fenur & Patella & Tibia & Metatorius u. Tarsus \\
\hline Be I & 3.0 & 1.0 & 2.8 & 6.9 \\
\hline B. II & 3.9 & 1.2 & 3.5 & 10.2 \\
\hline Be III & 3.1 & 1.0 & 2.8 & 7.8 \\
\hline Be. IV & 4.4 & 1.3 & 3.4 & 10.9
\end{tabular}

Fürbung: Der grösste Tell des Carapax, die lunenseiten der Stinkdrüsen, die Chitinplättchen, und das Scutum (es Männchens sind schwarzbraun oder schwarz, aber die weichhaütige Teile des Körpers sind hellrostgelb. Alle Extremitätenglieder sind schwarzbraun, aber die Femora basal weisslichgelb, und 2. Femur mit $3-6$, 3. Femur mit $0-4$, 4. Femur mit $3-6$ wcisslichen Ringelu.

Bemerkungen: Diese Art unterscheidet sich klar von del übrigen kekannten Arten derselken Gattuug durch die charakteristische der Cheliceren und Palpen (Die Bewehrung des Palpen-Patella des $\delta$ ) und durch die kesondere Bewehrung des Körpers.

Fundort: Berge Saraga-Miné (Ehimé-Keu) Juli 13. 1941 Larve 1, Okt. 26. 1941 \& 2, Nov. 9. 1941 क 1 und क 1.

Diese Art sei Dr. Ikio Sato gewidmet. Typus bei "The Arachnological Society of Eastern Asia" zu Tokyo. 